\title{
Analisa Pengaruh Pelayanan Terhadap Kepuasan Customer Dalam Menggunakan Jasa Pengiriman Barang Di JNE Pondok Kelapa
}

\author{
Achmad Sumbaryadi ${ }^{1}$, Nandang Iriadi $^{2}$, Fitrani Indah Yuliasari ${ }^{3}$ \\ ${ }^{1,2}$ Universitas Bina Sarana Informatika \\ e-mail: ${ }^{1}$ achmad.acs@bsi.ac.id, ${ }^{2}$ nandang.ndi@bsi.ac.id \\ ${ }^{3}$ Sekolah Tinggi Manajemen Informatika dan Komputer Nusa Mandiri \\ e-mail: ${ }^{3}$ fitrani_indah@yahoo.com

\begin{tabular}{ccc}
\hline Diterima & Direvisi & Disetujui \\
$11-04-2021$ & $13-04-2021$ & $19-05-2021$ \\
\hline
\end{tabular}

\begin{abstract}
Abstrak - Penelitian ini dilakukan untuk menganalisa pengaruh pelayanan kepuasaan pelaggan di JNE Agen Trimitra, dengan menggunakan teknik Data Mining Algoritma C4.5. Metode C4.5 dapat membantu perusahaan untuk mencari kelebihan dan kekurangan yang di berikan oleh perusahaan kepada pelanggan, hal ini sangat berguna bagi perusahaan untuk perencanaan kedepan bagi perusahaan. Untuk itu setiap perusahaan punya cara yang berbeda untuk melakukan penilaian atas tingkat kepuasan pelanggan. Dalam praktiknya, kegiatan penilaian atas tingkat kepuasan pelanggan harus dilakukan dengan metode yang baik dan tepat, sehingga tidak terjadi kesalahan dalam penilaian. Hasil penilaian yang dilakukan harus dapat dibuat sebenar-benarnya, sehingga pada gilirannya menumbuhkan loyalitas pelanggannya. Sistem pendukung keputusan merupakan alat bantu yang dapat digunakan untuk melakukan penilaian tingkat kepuasan pelanggan dengan cara memperbaki metode penilaian dari penentuan nilai harapan. Metode C4.5 di pilih untuk melakukan penilaian tingkat kepuasan pelanggan. Dari hasil pengujian dapat disimpulkan bahwa metode ini dapat diimplementasikan untuk penilaian tingkat kepuasan pelanggan sebagai acuan perusahaan untuk mengembangkan pelayanan di JNE Agen Trimitra.
\end{abstract}

Kata Kunci: Data Mining, Algoritma C4.5 , Pengaruh Pelayanan Kepuasaan Pelanggan.

Abstract - This study was conducted to analyze the effect of customer satisfaction services at JNE Agen Trimitra, using the Data Mining Algorithm C4.5 technique. The C4.5 method can help companies to find the advantages and disadvantages provided by the company to customers, this is very useful for companies for future planning for the company. For this reason, each company has a different way of assessing the level of customer satisfaction. In practice, the assessment of the level of customer satisfaction must be carried out with a good and appropriate method, so that there are no errors in the assessment. The results of the assessment carried out must be true, so that in turn it fosters customer loyalty. Decision support system is a tool that can be used to assess the level of customer satisfaction by improving the assessment method of determining the expected value. The C4.5 method was chosen to assess the level of customer satisfaction. From the test results, it can be concluded that this method can be implemented to assess the level of customer satisfaction as a reference for companies to develop services at JNE Agen Trimitra.

Keywords: Data Mining, C4.5 Algorithm, Effect of Customer Satisfaction Service.

\section{PENDAHULUAN}

Semakin banyaknya masyarakat yang menggunakan jasa pengiriman. maka kualitas pelayanan menjadi sangat penting untuk memenangkan persaingan. Dengan memahami apa yang diinginkan dan diharapkan oleh konsumen dari kualitas pelayanan yang diberikan, maka akan didapat suatu nilai tambah tersendiri bagi perusahaan tersebut. Kualitas pelayanan perlu mendapat perhatian besar dari perusahaan, karena kualitas pelayanan mempunyai hubungan langsung dengan kemampuan bersaing dan tingkat keuntungan perusahaan.

Kepuasan pelanggan adalah perasaan senang atau kecewa seorang yang merupakan hasil dari perbandingan dari persepsi kinerja produk dan harapannya. Kesetiaan pelanggan terhadap suatu perusahaan sangat perlu dipertahankan dan ditingkatkan. Ini berarti, kepuasan pelanggan merupakan awal dari terciptanya kepercayaan pelanggan tersebut terhadap perusahaan. Selain itu, untuk meningkatkan kepuasan, perusahaan harus menambah nilai yang dapat membuat para pelanggannya mendapatkan apa yang mereka bayar 
atau lebih dari yang mereka harapkan, sehingga mereka dapat bertahan dan mengarah pada pembelian ulang, perekomendasian, dan perekomendasian yang meningkat.

Hal ini sangat diperlukan, karena dengan mengetahui tingkat kepuasan pelanggan, secara otomatis pelanggan tersebut akan menjadi pelanggan setia diperusahaan dan menjadi pelanggan aktif yang berbelanja di perusahaan.Dengan mengetahui pelanggan aktif, perusahaan dapat mengetahui pendapatan tetap setiap periodenya. Untuk itu perlu adanya pengolahan data tentang pelanggan aktif, sehingga diketahui jumlah pelanggan aktif setiap periode tertentu. Jika jumlah pelanggan aktif bertambah maka diperlukan strategi untuk mempertahankan dan meningkatkan jumlahnya. Jika jumlah pelanggan aktif menurun, maka diperlukan strategi lain untuk meningkatkan jumlahnya.

\section{METODE PENELITIAN}

Menjelaskan kronologis penelitian, termasuk desain penelitian, prosedur penelitian (dalam bentuk algoritma, Pseudocode atau lainnya), bagaimana untuk menguji dan akuisisi data. Deskripsi dari program penelitian harus didukung referensi, sehingga penjelasan tersebut dapat diterima secara ilmiah.

\section{Data Mining}

Data mining adalah serangkaian proses untuk menggali nilai tambah berupa informasi yang selama ini tidak diketahui secara manual dari suatu basis data. Informasi yang dihasilkan diperoleh denga cara mengekstraksi dan mengenali pola yang penting atau menarik dari data yang terdapat pada basis data (Vulandari, 2017).

\section{Pohon Keputusan}

Pohon keputusan adalah pohon dalam analisis pemecahan masalah pengambilan keputusan adalah pemetaan mengenai alternatif - alternatif pemecahan masalah yang dapat diambil dari masalah tersebut. Pohon tersebut juga memperlihatkan faktor - faktor kemungkinan/probablitas yang akan mempengaruhi alternatif - alternatif keputusan tersebut, disertai dengan estimasi hasil akhir yang akan didapat bila kita mengambil alternatif keputusan tersebut (Vulandari, 2017).

\section{Algoritma C4.5}

Algoritma C45 untuk membangun pohon keputusan adalah sebagai berikut:

1. Pilih atribut sebagai akar

2. Buat cabang untuk masing-masing nilai

3. Bagi kasus dalam cabang

Ulangi proses untuk masing - masing cabang sampai semua kasus pada cabang memiliki kelas yang sama. (Vulandari,2017).

Adapun rumus menghitung nilai gain

$\operatorname{Gain}(\mathrm{S}, \mathrm{A})=\operatorname{Entropy}(\mathrm{S})-\sum_{t=1}^{n}\left|\frac{S i}{S}\right| \operatorname{Entropy}(\mathrm{Si})$
Keterangan :

$\mathrm{S}$ : Himpunan kasus

A : Atribut

$\mathrm{n}$ : Jumlah partisi atribut A

|Si| :Jumlah kasus pada partisi ke-i

$|\mathrm{S}|$ : Jumlah kasus dalam $\mathrm{S}$

Sedangkan perhitungan nilai entropy dapat dilihat pada rumus berikut :

$\operatorname{Entropy}(S)=(S)=\sum_{t=1}^{n}-p i X \quad \log _{2} p_{i}$

Keterangan :

$\mathrm{p}_{\mathrm{i}}$ : proporsi dari $\mathrm{S}_{\mathrm{i}}$ terhadap $\mathrm{S}$

\section{Metodologi Penelitian}

Metodologi penelitian diperlukan sebagai kerangka dan panduan dalam melakukan proses penelitian, sehingga penelitian yang di lakukan menjadi lebih terarah,teratur, dan sistematis.

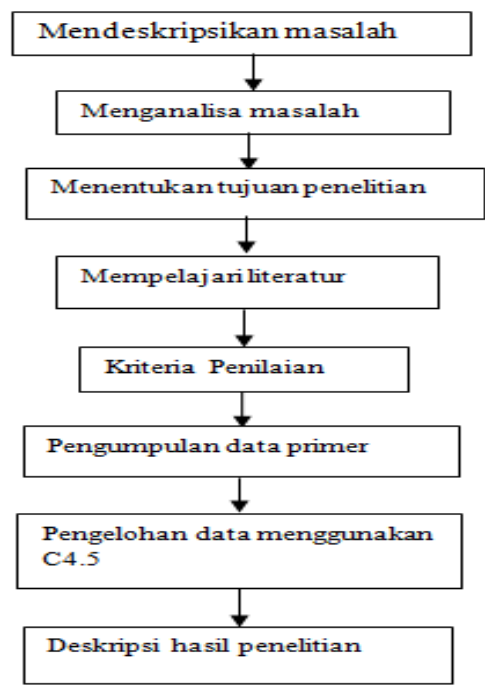

Gambar 2 Kerangka Kerja Peneliti

\section{HASIL DAN PEMBAHASAN}

Data yang akan diolah mempunyai beberapa kriteria yang merupakan syarat dalam pengolahan Data Mining dengan menggunakan teknik C4.5. Dimulai dengan perhitungan Entropy dan Gain untuk menentukan akar (root) dari pohon keputusan menganalisa pengaruh kepuasan pelanggan.

\section{Tabel 1}

\section{Data Kuesioner}

\section{(TERLAMPIR)}

Mengelompokkan nilai data kuesioner berdasarkan jawaban kuesioner yang dilakukan oleh responden, sehingga dapat di kelompokkan seperti tabel berikut. 
Tabel 2

Klasifikasi nilai

\begin{tabular}{|c|l|}
\hline Nilai & Klasifikasi \\
\hline $1-2$ & Tinggi \\
\hline $3-5$ & Rendah \\
\hline
\end{tabular}

Format data akhir setelah dilakukan praproses tampak seperti tabel berikut:

Tabel 3

\section{Format Data Akhir}

\section{(TERLAMPIR)}

Adapun langkah-langkah pembuatan pohon keputusan adalah sebagai berikut :

Menghitung nilai Entropy total:

Entropy $($ total $)=\left(-\frac{27}{40}+\log _{2}\left(\frac{27}{40}\right)\right)+\left(-\frac{13}{40}+\right.$ $\left.\log _{2}\left(\frac{13}{40}\right)\right)=0,909736$

Menghitung nilai Gain :

Gain(total, Tangible)

$$
\begin{aligned}
& =\operatorname{Entropy}(\mathrm{S})-\sum_{t=1}^{n}\left|\frac{S i}{S}\right| \operatorname{Entropy}(S i) \\
& =\quad 0,909736-\quad\left(\left(\frac{6}{40}\right) *(0,650022)\right)+\left(\left(\frac{34}{40}\right) *\right. \\
& (0,787127)) \\
& =0,143175
\end{aligned}
$$

Berikut adalah analisa atribut,nilai, banyaknya nilai kejadian, Entropy dan Gain.

\section{a. Tangible}

Berikut adalah data analisa nilai Entropy dan

\begin{tabular}{|c|c|c|c|c|c|c|c|}
\hline NODE & & & $\begin{array}{c}\text { Jumlah } \\
\text { kasus (s) }\end{array}$ & $\begin{array}{c}\text { Tidak } \\
\text { Puas (S1) }\end{array}$ & Puas(S2) & Entropy & Gain \\
\hline \multicolumn{2}{|r|}{\begin{tabular}{l|l}
1 & TOTAL \\
\end{tabular}} & & 40 & 13 & 27 & 0,909736 & \\
\hline \multicolumn{3}{|c|}{ Tangible } & & & & & 0,143175 \\
\hline & & Rendah & 6 & 5 & 1 & 0,650022 & \\
\hline & & Tinggi & 34 & 8 & 26 & 0,787127 & \\
\hline & \multicolumn{2}{|c|}{ Reliability } & & & & & 0,066765 \\
\hline \multicolumn{3}{|r|}{ Rendah } & 16 & 8 & 8 & 1 & \\
\hline \multicolumn{3}{|r|}{ Tinggi } & 24 & 5 & 19 & 0,738285 & \\
\hline \multicolumn{3}{|c|}{ Responiveness } & & & & & 0,019273 \\
\hline \multicolumn{3}{|r|}{ Rendah } & 13 & 8 & 5 & 0,961237 & \\
\hline \multicolumn{3}{|r|}{ Tinggi } & 29 & 7 & 22 & 0,797327 & \\
\hline \multicolumn{3}{|c|}{ Assurance } & & & & & 0,069827 \\
\hline \multicolumn{3}{|r|}{ Rendah } & 8 & 5 & 3 & 0,954434 & \\
\hline \multicolumn{3}{|r|}{ Tinggi } & 32 & 8 & 24 & 0,811278 & \\
\hline \multicolumn{3}{|c|}{ Empaty } & & & & & 0,063292 \\
\hline \multicolumn{3}{|r|}{ Rendah } & 6 & 4 & 2 & 0,918296 & \\
\hline \multicolumn{3}{|r|}{ Tinggi } & 34 & 9 & 25 & 0,833765 & \\
\hline
\end{tabular}
Gain tangible :

Table 5

Data Analisa Tangible

\section{b. Reliability}

Berikut adalah data analisa nilai Entropy dan

\begin{tabular}{|c|c|c|c|c|c|c|c|}
\hline NODE & & & \begin{tabular}{|l} 
Jumlah \\
kasus (s)
\end{tabular} & \begin{tabular}{|c|} 
Tidak \\
Puas (S1 \\
\end{tabular} & Puas(S2 & Entropy & Gain \\
\hline \multirow{2}{*}{\multicolumn{3}{|c|}{\begin{tabular}{l|l|l|}
1 & TOTAL & \\
& \multicolumn{2}{|c|}{ Reliability }
\end{tabular}}} & 34 & & 2 & \begin{tabular}{|l|l|}
6 & 0,787127 \\
\end{tabular} & \\
\hline & & & & & & & 0,020409 \\
\hline & & Rendah & 12 & & 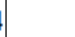 & 80,918296 & \\
\hline & & Tinggi & 22 & & 4 & \begin{tabular}{|l|l|}
8 & 0,684038 \\
\end{tabular} & \\
\hline \multicolumn{3}{|c|}{ Responiveness } & & & & & 0,002557 \\
\hline \multicolumn{3}{|r|}{ Rendah } & 7 & & 2 & \begin{tabular}{|l|l|}
5,863121 \\
\end{tabular} & \\
\hline \multicolumn{3}{|r|}{ Tinggi } & 27 & & 6 & 10,764205 & \\
\hline \multicolumn{3}{|c|}{ Assurance } & & & & & 0,016994 \\
\hline \multicolumn{3}{|r|}{ Rendah } & 5 & & 2 & \begin{tabular}{|l|l|}
3 & 0,970951 \\
\end{tabular} & \\
\hline \multicolumn{3}{|r|}{ Tinggi } & 29 & & 6 & \begin{tabular}{|l|l|}
3 & 0,735509 \\
\end{tabular} & \\
\hline \multicolumn{3}{|c|}{ Empaty } & & & & & 0,003468 \\
\hline \multicolumn{3}{|r|}{ Rendah } & 3 & 8 & 1 & 20,918296 & \\
\hline \multicolumn{3}{|r|}{ Tinggi } & 31 & & 7 & $4 \mid 0,770629$ & \\
\hline
\end{tabular}
Gain reliability :

Table 6

Data Analisa Reliability

\section{c. Empaty}

Berikut adalah data analisa nilai Entropy dan Gain Empaty:

Table 4

Data Analisa Empaty

\begin{tabular}{|r|r|r|r|r|r|r|r|}
\hline NODE & & & $\begin{array}{c}\text { Jumlah } \\
\text { kasus (5) }\end{array}$ & $\begin{array}{c}\text { Tidak } \\
\text { Puas (S1) }\end{array}$ & Puas(S2) & Entropy & Gain \\
\hline 1 & TOTAL & & 12 & 4 & 8 & 0,918296 & \\
\hline & Responiveness & & & & & 0 \\
\hline & Rendah & 3 & 1 & 2 & 0,918296 & \\
\hline & Tinggi & 9 & 3 & 6 & 0,918296 & \\
\hline & Assurance & & & & & 0,01722 \\
\hline & Rendah & 2 & 1 & 1 & 1 & \\
\hline & Tinggi & 10 & 3 & 7 & 0,881291 & \\
\hline & Empaty & & & & & 0,143391 \\
\hline & Rendah & 1 & 1 & 0 & 0 & \\
\hline & Tinggi & 11 & 3 & 8 & 0,845351 & \\
\hline
\end{tabular}

\section{d. Assurance}

Berikut adalah data analisa nilai Entropy dan Gain assurance :

Table 7

Data Analisa Assurance

\begin{tabular}{|r|r|r|r|r|r|r|r|}
\hline NODE & & & $\begin{array}{c}\text { Jumlah } \\
\text { kasus (s) }\end{array}$ & $\begin{array}{c}\text { Tidak } \\
\text { Puas (S1) }\end{array}$ & Puas(S2) & Entropy & Gain \\
\hline \multicolumn{2}{|c|}{ 1 } & TOTAL & 11 & 3 & 8 & 0,845351 & \\
\hline \multicolumn{2}{|r|}{ Responiveness } & & & & & 0,004886 \\
\hline & Rendah & 3 & 1 & 2 & 0,918296 & \\
\hline & Tinggi & 8 & 2 & 6 & 0,811278 & \\
\hline & Assurance & & & & & 0,038275 \\
\hline & Rendah & 2 & 1 & 1 & 1 & \\
\hline & Tinggi & 9 & 2 & 7 & 0,764205 & \\
\hline & & & & & & & \\
\hline
\end{tabular}




\section{e. Responiveness}

Berikut adalah data analisa nilai Entropy dan Gain responiveness :

Table 8

Data Analisa Responiveness

\begin{tabular}{|r|r|r|r|r|r|r|r|}
\hline NODE & & $\begin{array}{c}\text { Jumlah } \\
\text { kasus (s) }\end{array}$ & $\begin{array}{c}\text { Tidak } \\
\text { Puas } \\
(S 1)\end{array}$ & Puas(S2) & Entropy & Gain \\
\hline 1 & TOTAL & 2 & 1 & 1 & 1 & \\
\hline & \multicolumn{2}{|r|}{ Responiveness } & & & & & 0 \\
\hline & Rendah & 1 & 1 & 0 & 0 & \\
\hline & Tinggi & 1 & 0 & 1 & 0 & \\
\hline
\end{tabular}

\section{Pohon Keputusan}

Berikut adalah gambar pohon keputusan berdasarkan analisa atribut,nilai, banyaknya nilai kejadian, Entropy dan Gain :

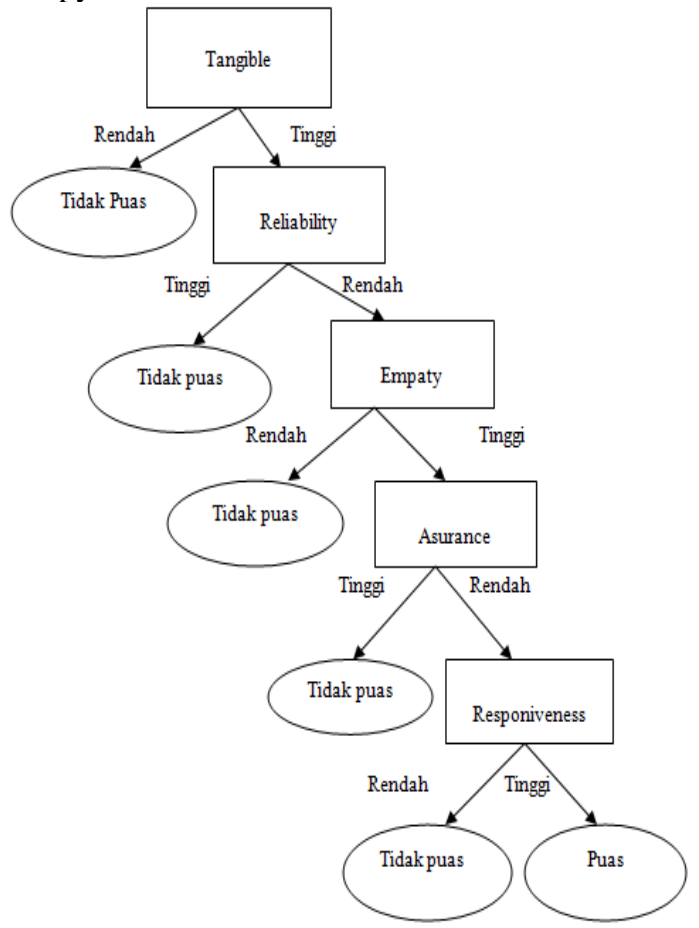

Gambar 2 Rule Pohon Keputusan

Adapun aturan rule yang terbentuk berdasarkan pohon keputusan terakhir seperti pada gambar .1 di atas adalah sebagai berikut :

1. Jika tnagible $=$ tinggi maka puas.

2. Jika tangible $=$ rendah maka tidak puas

3. Jika tangible $=$ tinggi dan reliability = tinggi maka tidak puas.

4. Jika tangible $=$ tinggi dan reability $=$ rendah maka puas.

5. Jika tangible $=$ tinggi dan reability $=$ rendah dan empaty $=$ tinggi maka puas.
6. Jika tangible $=$ tinggi dan reability $=$ rendah dan empaty $=$ rendah maka tidak puas.

7. Jika tangible $=$ tinggi dan reability $=$ rendah dan empaty = tinggi dan assurance $=$ rendah maka puas.

8. Jika tangible $=$ tinggi dan reability $=$ rendah dan empaty = tinggi dan assurance = tinggi maka tidak puas.

9. Jika tangible $=$ tinggi dan reability $=$ rendah dan empaty = tinggi dan assurance $=$ rendah dan responiveness $=$ tinggi maka puas.

10. Jika tangible $=$ tinggi dan reability $=$ rendah dan empaty = tinggi dan assurance $=$ rendah dan responiveness $=$ rendah maka tidak puas.

\section{KESIMPULAN}

Dari hasil penelitian dapat diambil kesimpulan yaitu:Algoritma C4.5 dapat menghasilkan rule untuk menggambarkan proses menggambarkan proses yang terkait dengan pelanggan puas dan tidak puas,Setelah di lakukan penelitian dari beberapa kriteria penilaian paling dominan adalah tangibles di Agen Jne Trimitra,Pada penelitian ini, penulis hanya mencoba salah satu teknik yaitu decision tree. Untuk mendapatkan hasil yang lebih baik lagi, dapat digunakan beberapa teknik data mining lainnya, Metode pohon keputusan yang diproses dengan WEKA lebih mudah membantu perusahaan menganalisa kepuasaan pelanggan.

\section{REFERENSI}

Jamhur, Annisak Izzaty. 2016. Penerapan Data Mining Untuk Menganalisa Jumlah Pelanggan Aktif Dengan Menggunakan Algoritma C4.5. Vol.23 No.2, Oktober 2016

Oktafianto. 2016. Analisi Kepuasan Mahasiswa Terhadap Pelayanan Akademik Menggunakan Metode Algoritma C4.5. ISSN: 2442-5567

Prasetyo, Eko. 2012. Data Mining Konsep Dan Aplikasi Menggunakan 4] MATLAB. Yogyakarta: Andi Yogyakarta.

Sugiono. 2016. Metode Penelitian Pendidikan Pendekatan Kuantitaf,Kualitaf, Dan $R \& D$. Bandung: Alfabeta Cv

Vulandari, Retno Tri. 2017. Data Mining Teori Dan Aplikasi Rapidminer. Yogyakarta: Gava Media.

Yuliana, ade dkk.2017. Algoritma Decision Tree (C4.5) Untuk Memprediksi Kepuasan Mahasiswa Terhadap Kinerja Dosen Politeknik TEDC Bandung.ISSN : 2549-7952. 


\section{LAMPIRAN}

Tabel 1

Data Kuesioner

\begin{tabular}{|c|c|c|c|c|c|c|c|c|c|c|c|c|c|c|c|c|c|c|c|c|c|c|c|c|c|c|}
\hline \multirow{2}{*}{ NO } & \multirow{2}{*}{ Nama } & \multirow{2}{*}{ umur $[\mathrm{Jt}$} & \multicolumn{24}{|c|}{ Nilai Kreteria } \\
\hline & & & P1 & P2 P & P3 & & & P4 & $05 \mathrm{P}$ & p6 & & & P7 F & P8 & pg & P10 & & P11 & P12 P. & 13 & & & \begin{tabular}{|l|l|l} 
P14 & P \\
\end{tabular} & P15 & & PUAS \\
\hline & 1 syahrul Ramadhan & $21 \mathrm{~L}$ & 1 & 2 & 1 & 1,333333 & TINGGI & 1 & 2 & 2 & 1,666667 & TINGGI & 2 & 2 & 2 & 2 & \begin{tabular}{l|l} 
Tinggi \\
\end{tabular} & 2 & 2 & 1 & 1,666667 & TINGG & 2 & 2 & 2 TINGGI & PUAS \\
\hline & 2 sari purnama & $32 \mathrm{p}$ & 1 & 2 & 2 & 1,666667 & TINGGI & 1 & 2 & 2 & 1,666667 & TINGGI & 2 & 3 & 2 & 2 & \begin{tabular}{l|l|}
2,3 & Rendah \\
\end{tabular} & 4 & 2 & 2 & & TINGGI & 2 & 2 & 2 TINGGI & PUAS \\
\hline & 3 annisa listya sari & $\begin{array}{lll}43 & p \\
\end{array}$ & 3 & 3 & 4 & 3,333333 & RENDAH & 2 & 2 & 2 & & TINGGI & 2 & 4 & 3 & 3 & 3 Rendah & 3 & 2 & 2 & 2,333333 & RENDAH & 2 & 2 & \begin{tabular}{|l|l|} 
TINGGI \\
\end{tabular} & TIDAK PUAS \\
\hline & 4 ahda fairisa savinka & $14 \mathrm{P}$ & 1 & 2 & 1 & 1,333333 & TINGGI & 2 & 2 & 2 & & TINGGI & 3 & 4 & 2 & 2 & \begin{tabular}{|l|l|}
2,8 & Rendah \\
\end{tabular} & 3 & 3 & 2 & 2,666667 & RENDAH & 2 & 2 & 2 TINGGI & TIDAK PUAS \\
\hline & 5 indira sahwas & $13 \mathrm{P}$ & 2 & \begin{tabular}{|l|}
2 \\
\end{tabular} & 2 & 1,666667 & TINGGI & 2 & 2 & 2 & & TINGGI & 2 & 2 & 2 & 2 & 2 Tinggi & 2 & 2 & 2 & , & TINGGI & 2 & 2 & \begin{tabular}{|l|l|} 
TINGGI \\
\end{tabular} & PUAS \\
\hline & 6 alex & $29 \mathrm{~L}$ & 1 & 2 & 1 & 1,333333 & TINGGI & 2 & 2 & 2 & & TINGGI & 2 & 2 & 2 & 2 & 2 Tinggi & - & 2 & 2 & ) & TINGG & 2 & 2 & \begin{tabular}{|l|l|}
2 & TINGGI \\
\end{tabular} & PUAS \\
\hline & 7 bayu irawan & $22 \mathrm{~L}$ & 1 & 2 & 1 & 1,333333 & TINGGI & 3 & 2 & 2 & 2,333333 & RENDAH & 2 & 2 & 2 & 2 & 2 Tinggi & 1 & 2 & 1 & 1,333333 & TINGGI & 2 & 2 & \begin{tabular}{|l|l|} 
& TINGGI \\
\end{tabular} & PUAS \\
\hline & 8 dwina aprillia putri & $20 \mathrm{p}$ & 2 & 21 & 2 & 1,666667 & 7 TINGGI & 2 & 3 & 2. & 2,333333 & RENDAH & 2 & 2 & 2 & 2 & 2 Tinggi & 2 & 2 & 2 & & TINGGI & 2 & 2 & 2 TINGGI & TIDAK PUAS \\
\hline & 9 sariah & $\begin{array}{lll}43 & P \\
\end{array}$ & 2 & 21 & 1 & 1,333333 & TINGGI & 2 & 3 & 2 & 2,333333 & RENDAH & 2 & 3 & 2 & 2 & \begin{tabular}{l|l|}
2,3 & Rendah \\
\end{tabular} & 1 & 2 & 1 & 1,333333 & TINGGI & 2 & 2 & 2 TINGGI & PUAS \\
\hline & 0 hanapi & $48 \mathrm{~L}$ & 2 & 21 & 1 & 1,333333 & TINGGI & 2 & 2 & 3 & 2,333333 & RENDAH & 3 & 2 & 2 & 2 & \begin{tabular}{l|l|}
2,3 & Rendah \\
\end{tabular} & 2 & 2 & 2 & & TINGGI & 2 & 2 & 2 TINGGI & PUAS \\
\hline & 1 fernando marpaung & $20 \mathrm{~L}$ & 1 & 1 & 1 & & TINGGI & 2 & 2 & 2 & & TINGG & 2 & 1 & 2 & 1 & \begin{tabular}{l|l|l|}
1,5 & Tinggi \\
\end{tabular} & 1 & 2 & 2 & 1,666667 & TINGGI & 1 & 1 & 1 TINGGI & PUAS \\
\hline & 2 adi wijaya & $23 \mathrm{~L}$ & 2 & 22 & 2 & & TINGGI & 2 & 2 & 3. & 2,333333 & RENDAH & 1 & 2 & 2 & 2 & 1,8 Tinggi & 2 & 2 & 2 & & TINGGI & 2 & 2 & 2 TINGGI & PUAS \\
\hline & 3 intan purnama & $32 \mathrm{p}$ & 2 & 2 & 2 & & TINGGI & 2 & 2 & 2 & & TINGGI & 1 & 1 & 2 & 1 & \begin{tabular}{l|l}
1,3 Tinggi \\
\end{tabular} & 1 & 2 & 2 & 1,666667 & TINGGI & 2 & 1 & \begin{tabular}{|l|l|}
1,5 & TINGGI \\
\end{tabular} & PUAS \\
\hline & 4 septi rahmah & $45 \mathrm{P}$ & 2 & 22 & 2 & & TINGGI & 3 & 2 & 2 & 2,333333 & RENDAH & 1 & 1 & 2 & 1 & \begin{tabular}{l|l|}
1,3 & Tinggi \\
\end{tabular} & 2 & 2 & 2 & & TINGGI & 2 & 2 & 2 TINGGI & PUAS \\
\hline & 5 salas wiguna & $33 \mathrm{~L}$ & 1 & 1 & 3 & 1,666667 & TINGGI & 4 & 3 & 3 & 3,333333 & RENDAH & 3 & 3 & 3 & 1 & \begin{tabular}{l|l|}
2,5 & Rendah \\
\end{tabular} & 4 & 3 & 2 & & RENDAH & 3 & 1 & \begin{tabular}{|l|l|}
2 & TINGGI \\
\end{tabular} & TIDAK PUAS \\
\hline & 6 najip wibowo & $18 \mathrm{~L}$ & 1 & 2 & 2 & 1,666667 & TINGGI & 2 & 2 & 2 & & TINGGI & 2 & 2 & 2 & 1 & \begin{tabular}{l|l}
1,8 & Tinggi \\
\end{tabular} & 2 & 1 & 2 & 1,666667 & TINGGI & 2 & 2 & 2 TINGGI & PUAS \\
\hline & 7 risbi arianto & $24 \mathrm{~L}$ & 2 & 22 & 2 & & TINGGI & 2 & 3 & 3 & 2,666667 & RENDAH & 2 & 2 & 2 & 1 & \begin{tabular}{l|l}
1,8 Tinggi \\
\end{tabular} & 2 & 1 & 2 & 1,666667 & TINGGI & 2 & 1 & 1,5 TINGGI & PUAS \\
\hline & 8 riski rahmat & $40 \mathrm{~L}$ & 2 & 22 & 2 & & TINGGI & 2 & 2 & 2 & & TINGGI & 2 & 2 & 1 & 2 & \begin{tabular}{l|l|}
1,8 & Tinggi \\
\end{tabular} & 2 & 1 & 2 & 1,666667 & TINGGI & 2 & 2 & 2 TINGGI & TIDAK PUAS \\
\hline & 9 dimas rahmat & $34 \mathrm{~L}$ & 2 & 2 & 2 & & TINGGI & 1 & 1 & 2 & 1,333333 & TINGGI & 2 & 3 & 2 & 2 & \begin{tabular}{l|l|}
2,3 & Rendah \\
\end{tabular} & 2 & 1 & 2 & 1,666667 & TINGG & 2 & 2 & 2 TINGGI & PUAS \\
\hline & 0 susan martini & $25 \mathrm{p}$ & 2 & $2 \mid 2$ & 2 & & 2 TINGGI & 1 & 2 & 2 & 1,666667 & TINGG & 2 & 2 & 1 & 1 & 1,5 Tinggi & 2 & 2 & 2 & & TINGGI & 2 & 2 & \begin{tabular}{l|l|l}
2 & TINGGI \\
\end{tabular} & PUAS \\
\hline & rina septiani & \begin{tabular}{l|l}
18 & $\mathrm{P}$ \\
\end{tabular} & 3 & 3 & 43 & 3,333333 & \begin{tabular}{|l|} 
RENDAH \\
\end{tabular} & 3 & 2 & 2 & 2,333333 & RENDAH & 3 & 4 & 4 & 4 & \begin{tabular}{|l|l|}
3,8 & Rendah \\
\end{tabular} & 3 & 3 & 3 & & RENDAH & 4 & 3 & \begin{tabular}{|l|l|}
3,5 & RENDAH \\
\end{tabular} & TIDAK PUAS \\
\hline & nurdin ramadhan & \begin{tabular}{l|l}
$28 \mathrm{~L}$ \\
\end{tabular} & 2 & 2 & 2 & & TINGGI & 2 & 2 & 2 & & TINGGI & 2 & 2 & 2 & 2 & \begin{tabular}{l|l}
2 & Tinggi \\
\end{tabular} & 2 & 2 & 4 & 2,666667 & RENDAH & 2 & 2 & \begin{tabular}{|l|l|}
2 & TINGGI \\
\end{tabular} & PUAS \\
\hline & muhamad anas & \begin{tabular}{l|l|}
22 & $\mathrm{~L}$ \\
\end{tabular} & 2 & 2 & 2 & & TINGGI & 1 & 2 & 2. & 1,666667 & TINGGI & 2 & 2 & 2 & 1 & \begin{tabular}{l|l|}
1,8 & Tinggi \\
\end{tabular} & 2 & 2 & 2 & & TINGGI & 2 & 1 & \begin{tabular}{|l|l|}
1,5 & TINGGI \\
\end{tabular} & TIDAK PUAS \\
\hline & wijaya sakti & $\begin{array}{ll}35 \mathrm{~L} \\
\end{array}$ & 1 & 2 & 2.1 & 1,666667 & TINGGI & 1 & 3 & $3:$ & 2,333333 & RENDAH & 2 & 2 & 2 & 2 & 2 Tinggi & 2 & 2 & 2 & & TINGGI & 2 & 1 & \begin{tabular}{|l|l|}
1,5 & TINGGI \\
\end{tabular} & TIDAK PUAS \\
\hline & beni susanto & $\begin{array}{lll}23 \mathrm{~L} \\
\end{array}$ & 1 & 2 & 21 & 1,666667 & TINGGI & 1 & 3 & 32 & 2,333333 & RENDAH & 2 & 2 & 2 & 1 & \begin{tabular}{l|l}
1,8 & Tinggi \\
\end{tabular} & 2 & 2 & 2 & & TINGGI & 2 & 2 & \begin{tabular}{|l|l|}
2 & TINGGI \\
\end{tabular} & PUAS \\
\hline & muma safira & \begin{tabular}{l|l}
15 & $\mathrm{P}$ \\
\end{tabular} & 1 & 2 & 21 & 1,666667 & TINGGI & 2 & 3 & 4 & & RENDAH & 2 & 2 & 2 & 2 & \begin{tabular}{l|l}
2 & Tinggi \\
\end{tabular} & 2 & 3 & 2 & 2,333333 & RENDAH & 2 & 2 & 2 TINGGI & PUAS \\
\hline & rahmat fauzi & \begin{tabular}{l|l}
$23 \mathrm{~L}$ \\
\end{tabular} & 1 & 1 & 21 & 1,333333 & TINGGI & 2 & 2 & 2 & & TINGGI & 2 & 2 & 2 & 2 & \begin{tabular}{l|l}
2 & Tinggi \\
\end{tabular} & 2 & 2 & 2 & & TINGGI & 2 & 3 & \begin{tabular}{|l|l|}
2,5 & RENDAH \\
\end{tabular} & PUAS \\
\hline & syifa fauziah & \begin{tabular}{l|l|}
22 & $\mathrm{P}$ \\
\end{tabular} & 2 & 2 & 2 & & TINGGI & 2 & 2 & 2 & & TINGGI & 2 & 2 & 2 & 1 & \begin{tabular}{l|l}
1,8 & Tinggi \\
\end{tabular} & 2 & 2 & 2 & & TINGGI & 2 & 2 & \begin{tabular}{|l|l|}
2 & TINGGI \\
\end{tabular} & TIDAK PUAS \\
\hline & citra trinovi & \begin{tabular}{l|l}
22 & $p$ \\
\end{tabular} & 2 & 2 & 2 & & TINGGI & 2 & 1 & 1. & 1,333333 & TINGGI & 2 & 3 & 2 & 2 & \begin{tabular}{l|l|}
2,3 & Rendah \\
\end{tabular} & 1 & 2 & 2 & 1,666667 & TINGGI & 3 & 2 & \begin{tabular}{l|l|}
2,5 & RENDAH \\
\end{tabular} & PUAS \\
\hline & subhan hamidi & $35 \mathrm{~L}$ & 2 & 2 & 2 & & TINGGI & 2 & 1 & 2. & 1,666667 & TINGGI & 2 & 2 & 2 & 1 & \begin{tabular}{l|l}
1,8 & Tinggi \\
\end{tabular} & 1 & 2 & 2 & 1,666667 & TINGGI & 2 & 2 & \begin{tabular}{|l|l|}
2 & TINGGI \\
\end{tabular} & PUAS \\
\hline & sahlul gunawan & \begin{tabular}{l|l}
$45 \mathrm{~L}$ \\
\end{tabular} & 3 & 3 & 3 & & RENDAH & 4 & 3 & 3 & 3,333333 & RENDAH & 1 & 3 & 3 & 3 & \begin{tabular}{|l|l|}
2,5 & Rendah \\
\end{tabular} & 2 & 2 & 2 & & TINGGI & 2 & 2 & \begin{tabular}{|l|l|} 
TINGGI \\
\end{tabular} & TIDAK PUAS \\
\hline & muhammad fahri & $\begin{array}{lll}37 \mathrm{~L} \\
\end{array}$ & 3 & 2 & 2. & 2,333333 & RENDAH & 3 & 4 & $4:$ & 3,666667 & RENDAH & 1 & 3 & 3 & 3 & \begin{tabular}{l|l|}
2,5 & Rendah \\
\end{tabular} & 1 & 3 & 2 & & TINGGI & 2 & 3 & \begin{tabular}{|l|l|}
2,5 & RENDAH \\
\end{tabular} & TIDAK PUAS \\
\hline & mawadah safitri & \begin{tabular}{l|l}
25 & $P$ \\
\end{tabular} & 2 & 2 & 2 & & TINGGI & 1 & 2 & 2. & 1,666667 & TINGGI & 2 & 2 & 2 & 2 & 2 Tinggi & 7 & 2 & 2 & & TINGGI & 2 & 2 & 2 TINGGI & PUAS \\
\hline & amel puspita & \begin{tabular}{l|l|}
45 & $P$ \\
\end{tabular} & 3 & 3 & 3. & & RENDAH & 3 & 3 & 3 & & RENDAH & 1 & 2 & 1 & 2 & \begin{tabular}{l|l|}
1,5 & Tinggi \\
\end{tabular} & 2 & 3 & 2 & 2,333333 & RENDAH & 3 & 2 & \begin{tabular}{|l|l|}
2,5 & RENDAH \\
\end{tabular} & TIDAK PUAS \\
\hline & muhamad hadi & $22 \mathrm{~L}$ & 2 & 2 & 2 & & TINGGI & 2 & 2 & 2 & & TINGGI & 2 & 2 & 2 & 2 & 2 Tinggi & 2 & 2 & 2 & & TINGGI & 2 & 2 & \begin{tabular}{|l|l|}
2 & TINGGI \\
\end{tabular} & PUAS \\
\hline & jimmy prayoga & \begin{tabular}{l|l}
$45 \mathrm{~L}$ \\
\end{tabular} & 4 & 2 & 2 & 2,666667 & \begin{tabular}{|l|} 
RENDAH \\
\end{tabular} & 2 & 1 & 2 & 1,666667 & TINGGI & 2 & 2 & 1 & 2 & \begin{tabular}{l|l}
1,8 & Tinggi \\
\end{tabular} & 2 & 2 & 2 & & TINGGI & 2 & 2 & \begin{tabular}{|l|l|}
2 & TINGGI \\
\end{tabular} & PUAS \\
\hline & abdul rachman & $\begin{array}{lll}32 \mathrm{~L} \\
\end{array}$ & 2 & 2 & 2 & & TINGGI & 2 & 2 & 2 & & TINGGI & 1 & 2 & 2 & 2 & \begin{tabular}{l|l}
1,8 & Tinggi \\
\end{tabular} & 2 & 2 & 2 & & TINGGI & 2 & 2 & \begin{tabular}{|l|l|}
2 & TINGGI \\
\end{tabular} & PUAS \\
\hline & susanti pertiwi & \begin{tabular}{l|l}
23 & $\mathrm{P}$ \\
\end{tabular} & 2 & 2 & 2 & & TINGGI & 2 & 3 & 3 & 2,666667 & RENDAH & 2 & 2 & 1 & 1 & \begin{tabular}{l|l}
1,5 & Tinggi \\
\end{tabular} & 2 & 2 & 2 & & TINGGI & 3 & 2 & \begin{tabular}{|l|l|}
2,5 & RENDAH \\
\end{tabular} & TIDAK PUAS \\
\hline & zaki rahmat & $26 \mathrm{~L}$ & 2 & 2 & 2 & & TINGGI & 2 & 2 & 2 & 27 & TINGGI & 2 & 2 & 2 & 2 & \begin{tabular}{l|l|}
2 & Tinggi \\
\end{tabular} & 1 & 1 & 2 & 1,333333 & TINGGI & 2 & 2 & 2 TINGGI & PUAS \\
\hline & haris dermawan & $36 \mid \mathrm{L}$ & 2 & 1 & 2 & 1,666667 & TINGGI & 2 & 2 & 2 & & TINGGI & 2 & 2 & 2 & 1 & \begin{tabular}{l|l|}
1,8 & Tinggi \\
\end{tabular} & 2 & 3 & & 2,333333 & RENDAH & 2 & 2 & \begin{tabular}{|l|l|}
2 & TINGGI \\
\end{tabular} & PUAS \\
\hline
\end{tabular}


Tabel 3

Format Data Akhir

\begin{tabular}{|c|c|c|c|c|c|c|c|c|c|}
\hline \multirow{2}{*}{ NO } & \multirow{2}{*}{ Nama } & \multirow{2}{*}{ umur } & \multirow{2}{*}{ JK } & \multicolumn{6}{|c|}{ Nilaı Kreterıa } \\
\hline & & & & Tangible & Reliability & Responiveness & Assurance & Empaty & PUAS \\
\hline $1 \mathrm{~s}$ & syahrul Ramadhan & 21 & $\mathrm{~L}$ & TINGGI & TINGGI & Tinggi & TINGGI & TINGGI & PUAS \\
\hline $2 s$ & sari purnama & 32 & P & TINGGI & TINGGI & Rendah & TINGGI & TINGGI & PUAS \\
\hline $3:$ & annisa listya sari & 43 & $\mathrm{P}$ & RENDAH & TINGGI & Rendah & RENDAH & TINGGI & TIDAK PUAS \\
\hline 48 & ahda fairisa savinka & 14 & $\mathrm{P}$ & TINGGI & TINGGI & Rendah & RENDAH & TINGGI & TIDAK PUAS \\
\hline 5 i & indira sahwa s & 13 & $\mathrm{P}$ & TINGGI & TINGGI & Tinggi & TINGGI & TINGGI & PUAS \\
\hline 6 & alex & 29 & $\mathrm{~L}$ & TINGGI & TINGGI & Tinggi & TINGGI & TINGGI & PUAS \\
\hline $7 \mathrm{~b}$ & bayu irawan & 22 & $\mathrm{~L}$ & TINGGI & RENDAH & Tinggi & TINGGI & TINGGI & PUAS \\
\hline 8 & dwina aprillia putri & 20 & $\mathrm{P}$ & TINGGI & RENDAH & Tinggi & TINGGI & TINGGI & TIDAK PUAS \\
\hline 95 & sariah & 43 & P & TINGGI & RENDAH & Rendah & TINGGI & TINGGI & PUAS \\
\hline $10 \mathrm{r}$ & hanapi & 48 & $\mathrm{~L}$ & TINGGI & RENDAH & Rendah & TINGGI & TINGGI & PUAS \\
\hline $11 \mathrm{f}$ & fernando marpaung & 20 & $\mathrm{~L}$ & TINGGI & TINGGI & Tinggi & TINGGI & TINGGI & PUAS \\
\hline 12 & adi wijaya & 23 & $\mathrm{~L}$ & TINGGI & RENDAH & Tinggi & TINGGI & TINGGI & PUAS \\
\hline 13 i & intan purnama & 32 & $\mathrm{P}$ & TINGGI & TINGGI & Tinggi & TINGGI & TINGGI & PUAS \\
\hline $14 \mathrm{~s}$ & septi rahmah & 45 & $\mathrm{P}$ & TINGGI & RENDAH & Tinggi & TINGGI & TINGGI & PUAS \\
\hline $15 \mathrm{~s}$ & salas wiguna & 33 & $\mathrm{~L}$ & TINGGI & RENDAH & Rendah & RENDAH & TINGGI & TIDAK PUAS \\
\hline $16 r$ & najip wibowo & 18 & $\mathrm{~L}$ & TINGGI & TINGGI & Tinggi & TINGGI & TINGGI & PUAS \\
\hline $17 r$ & risbi arianto & 24 & $\mathrm{~L}$ & TINGGI & RENDAH & Tinggi & TINGGI & TINGGI & PUAS \\
\hline $18 r$ & riski rahmat & 40 & L & TINGGI & TINGGI & Tinggi & TINGGI & TINGGI & TIDAK PUAS \\
\hline 19 c & dimas rahmat & 34 & $\mathrm{~L}$ & TINGGI & TINGGI & Rendah & TINGGI & TINGGI & PUAS \\
\hline 20 & susan martini & 25 & $\mathrm{P}$ & TINGGI & TINGGI & Tinggi & TINGGI & TINGGI & PUAS \\
\hline 21 & rina septiani & 18 & $\mathrm{P}$ & RENDAH & RENDAH & Rendah & RENDAH & RENDAH & TIDAK PUAS \\
\hline 22 & nurdin ramadhan & 28 & L & TINGGI & TINGGI & Tinggi & RENDAH & TINGGI & PUAS \\
\hline 23 & muhamad anas & 22 & $\mathrm{~L}$ & TINGGI & TINGGI & Tinggi & TINGGI & TINGGI & TIDAK PUAS \\
\hline 24 & wijaya sakti & 35 & L & TINGGI & RENDAH & Tinggi & TINGGI & TINGGI & TIDAK PUAS \\
\hline 25 & beni susanto & 23 & $\mathrm{~L}$ & TINGGI & RENDAH & Tinggi & TINGGI & TINGGI & PUAS \\
\hline 26 & muma safira & 15 & $P$ & TINGGI & RENDAH & Tinggi & RENDAH & TINGGI & PUAS \\
\hline 27 & rahmat fauzi & 23 & L & TINGGI & TINGGI & Tinggi & TINGGI & RENDAH & PUAS \\
\hline 28 & syifa fauziah & 22 & $P$ & TINGGI & TINGGI & Tinggi & TINGGI & TINGGI & TIDAK PUAS \\
\hline 29 & citra trinovi & 22 & P & TINGGI & TINGGI & Rendah & TINGGI & RENDAH & PUAS \\
\hline 30 & subhan hamidi & 35 & L & TINGGI & TINGGI & Tinggi & TINGGI & TINGGI & PUAS \\
\hline 31 & sahlul gunawan & 45 & L & RENDAH & RENDAH & Rendah & TINGGI & TINGGI & TIDAK PUAS \\
\hline 32 & muhammad fahri & 37 & $\mathrm{~L}$ & RENDAH & RENDAH & Rendah & TINGGI & RENDAH & TIDAK PUAS \\
\hline 33 & mawadah safitri & 25 & $P$ & TINGGI & TINGGI & Tinggi & TINGGI & TINGGI & PUAS \\
\hline 34 & amel puspita & 45 & $P$ & RENDAH & RENDAH & Tinggi & RENDAH & RENDAH & TIDAK PUAS \\
\hline 35 & muhamad hadi & 22 & $\mathrm{~L}$ & TINGGI & TINGGI & Tinggi & TINGGI & TINGGI & PUAS \\
\hline 36 & jimmy prayoga & 45 & L & RENDAH & TINGGI & Tinggi & TINGGI & TINGGI & PUAS \\
\hline 37 & abdul rachman & 32 & L & TINGGI & TINGGI & Tinggi & TINGGI & TINGGI & PUAS \\
\hline 38 & susanti pertiwi & 23 & $P$ & TINGGI & RENDAH & Tinggi & TINGGI & RENDAH & TIDAK PUAS \\
\hline 39 & zaki rahmat & 26 & $\mathrm{~L}$ & TINGGI & TINGGI & Tinggi & TINGGI & TINGGI & PUAS \\
\hline 40 & haris dermawan & 36 & $\mathrm{~L}$ & TINGGI & TINGGI & Tinggi & RENDAH & TINGGI & PUAS \\
\hline
\end{tabular}

